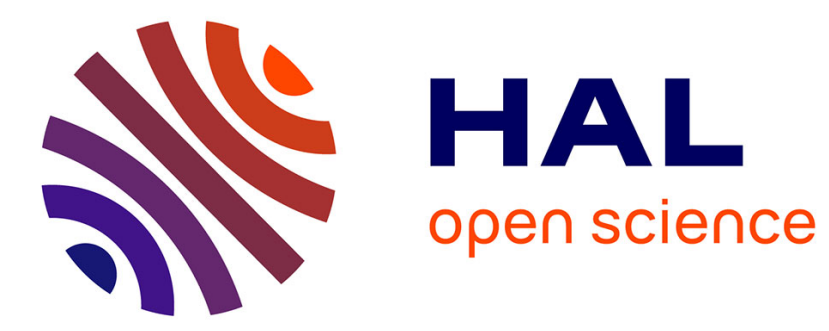

\title{
INTERSTITIAL SOLUTE ANELASTICITY AND MECHANICAL BEHAVIOR OF GROUP Vb METALS
}

R. Gibala

\section{To cite this version:}

R. Gibala. INTERSTITIAL SOLUTE ANELASTICITY AND MECHANICAL BEHAVIOR

OF GROUP Vb METALS. Journal de Physique Colloques, 1985, 46 (C10), pp.C10-43-C10-46. 10.1051/jphyscol:19851009. jpa-00225298

\section{HAL Id: jpa-00225298 https://hal.science/jpa-00225298}

Submitted on 1 Jan 1985

HAL is a multi-disciplinary open access archive for the deposit and dissemination of scientific research documents, whether they are published or not. The documents may come from teaching and research institutions in France or abroad, or from public or private research centers.
L'archive ouverte pluridisciplinaire HAL, est destinée au dépôt et à la diffusion de documents scientifiques de niveau recherche, publiés ou non, émanant des établissements d'enseignement et de recherche français ou étrangers, des laboratoires publics ou privés. 
Colloque C10, supplément au $\mathrm{n}^{\circ} 12$, Tome 46 , décembre 1985 page Cl0-43

\title{
INTERSTITIAL SOLUTE ANELASTICITY AND MECHANICAL BEHAVIOR OF GROUP Vb METALS
}

\author{
R. GIBALA \\ Department of Materials and Metallurgical Engineering, The \\ University of Michigan, Ann Arbor, M.I. 48109, U.S.A.
}

\begin{abstract}
An argument is presented that the difference in Snoek-related anelastic behavior of the Group $\mathrm{Vb}$ metals $\mathrm{Nb}$ and $\mathrm{Ta}$ observed by Weller and co-workers vis-a-vis Powers and Doyle, Gibala and Wert and other investigators is related to metal purity. Weller's results are unique in their use of very high purity base metals. These materials apparently do not exhibit the discrete anelastic relaxations of interstitial solute singles, pairs, triplets and other small atom clusters observed by other investigators in materials of lesser purity. This analysis of anelastic data is consistent with mechanisms of solute association effects which have been used to account for solid solution softening observed in mechanical behavior data on $\mathrm{Nb}$ - and Ta-base ternary alloys.
\end{abstract}

I - BACKGROUND

An apparent discrepancy exists in the 1iterature between recent anelastic investigations by Weller et a1. and several other investigators /2-9/ on the nature of binary interstitial solid solutions of the Group $\mathrm{Vb}$ metals $\mathrm{Nb}$ and Ta. Weller's data on $\mathrm{Nb}-\mathrm{O}$ and $\mathrm{Ta}-\mathrm{O}$ alloys are consistent with a broad spectrum of relaxation events over a wide range of interstitial concentrations. Internal friction peaks are either Debye-1ike at low solute concentrations or are symmetrically broadened and fitted well to a lognormal distribution of relaxation times /10/ at higher concentrations. Correspondingly, strain relaxation data are wel1described by a simple exponential decay at low concentrations and a lognormal decay as the interstitial concentration is increased. By contrast, many other results on higher concentration alloys, dating back to early investigations by Powers and Doyle /2/ and Gibala and Wert $/ 4,5 /$, have been successfully and self-consistently analyzed in terms of discrete relaxation events. These investigations have identified relaxations which involve the independent stress-induced reorientations of single interstitial solutes (the Snoek relaxation), solute pairs, triplets and perhaps higher order complexes. At lower concentrations, or at higher temperatures where the complexes are thermally dissociated, the relaxation behavior becomes more Debye-1ike /11-13/.

Recent investigations by Okamoto /8/ and Cost /9/ have confirmed the earlier findings in nearly quantitative detail. Okamoto reinvestigated the $\mathrm{Nb}-\mathrm{O}$ system examined extensively by Gibala and Wert /4/ and obtained a comparable set of four discrete relaxations from detailed analysis of strain relaxation data. Cost reanalyzed the Gibala-Wert strain relaxation data comprehensively by computer techniques and concluded that the original data were properly analyzed. Several years ago, Tewari /14/ had argued that the Gibala-Wert data could be analyzed alternatively by a lognormal distribution of relaxation times, although simple examination of figures in his paper discloses lack of fit that is we 11 outside the range of possible experimental error. Cost has argued that the strain relaxation results of Weller and similar ones by Boratto and Reed-Hill $115 /$ were influenced by the limited range of times over which the strain relaxation behavior was examined. He dismissed the possibility of purity having a role in the differences in results. 
This paper presents a re-examination of these internal friction and strain relaxation data. The analysis is performed both in the context of an anelasticity problem and a problem of importance to the understanding of the mechanical behavior of bcc metals which contain interstitial solutes /16/. We conclude that while there may be uncertainties associated with the strain relaxation measurements made by Weller et al. and Boratto and Reed-Hill, as Cost maintains, effects of purity should not be ruled out.

\section{II - ANALYSIS}

Table 1 presents a summary of the investigative controversy described in section I. It should be noted that the evidence presented by the seven sets of investigators who argue in favor of discrete interstitial clusters in anelastic spectra is formidable. Not only do the results include research on several different alloy systems, but there is also substantial repetition on the single system $\mathrm{Nb}-\mathrm{O}$ to warrant the conclusion that asymmetric Snoek peak broadening by interstitial clustering is a substantiated result. On the other hand, the 1 ist of investigations which provides evidence for Debye-like or symmetrically broadened relaxation spectra is actually small. References 11-13 involve experiments on low concentration alloys and/or measurements at high temperatures at which solute clusters should dissociate thermally, given typical values of the binding enthalpies reported for these clusters. Tewari's analysis /14/ignored the high precision with which the strain relaxation measurements have been made. Boratto and Reed-Hill have not characterized their materials nor described adequately the details of their analysis of peak shapes or decay curves to give substantive evidence against discrete relaxation spectra. Truly, the lone investigation that argues forcefully in favor of non-discrete relaxation behavior is that of Weller et al.

Cost's argument that the strain relaxation results of Weller et al. may have been affected by the limited range of times over which the relaxation was measured is an effective one. Of equal importance is consideration of stress equilibration times for the alloy prior to experimental measurements. Anelastic strain relaxation measurements made at a given temperature must be preceeded by at least an equal amount of anelastic creep. Also, the material should be well equilibrated thermodynamically at zero applied stress prior, to the anelastic creep portion of the cycle. It should be verified that Weller's results are not biased by such hold-time effects. However, Cost's argument does not pertain and cannot be extended to Weller's internal friction data, which are obtained at very small equilibration and relaxation times. If Weller's strain relaxation results were biased by experimental equilibration effects, the strain relaxation and internal friction data would not be so complementary.

When one examines all of the data and experiments depicted in Table 1 , there is one factor involving Weller's research that distinguishes it from all other investigations, viz. his use of metals with very low substitutional solute contents and ultra-high vacuum purification techniques to remove other residual interstitial solutes. The high values of the residual resistivity ratios reported by Weller indicate use of truly binary $\mathrm{Nb}-\mathrm{O}$ and $\mathrm{Ta}-\mathrm{O}$ alloys. Other investigators have used materials which contained at least tens and most often hundreds of parts-per-miliion (atomic) of significant impurities. Consequently, Weller's results could represent the anelastic response of the pure binary alloy, e.g. (Nb)-O, whereas other results are biased strongly by the presence of binding effects of the interstitial with other solutes, e.g. $(\mathrm{Nb}+\mathrm{N})-0$. If this analysis is correct, then Weller's results are not incompatible with those of investigators listed in part A of Table 1. Both sets of results are accurate representations of the types of materials examined, $i . e$. pure vs. impure.

The implication of the above analysis is that the discrete clusters observed by investigators other than weller involve oxygen-impurity complexes. It also implies larger binding enthalpies than have been reported previously. To prove such a hypothesis requires data such as Weller's obtained on high purity dilute 
ternary alloys. Until such results are available, evidence for this hypothesis will remain circumstantial. Two such pieces of circumstantial evidence are given below.

We have examined the data of Gibala and Wert /4,5/ on $\mathrm{Nb}-\mathrm{O}$ alloys in detail for possible effects of purity. The only solute for which the concentration varied by significant measurable amounts is $\mathrm{N}$. A weak but positive correlation exists between the relaxation strength of the oxygen pair peak and the residual $\mathrm{N}$ concentration, as measured by the $\mathrm{N}$ Snoek relaxation, Fig. 1. These data suggest that $\mathrm{N}$ acts as a nucleation or stabilizing agent for oxygen cluster formation. Because $N$ is present in small concentrations compared to oxygen in these alloys, the binding enthalpy of such $\mathrm{O}_{\mathrm{n}} \mathrm{N}$ clusters must be larger than the $10-20 \mathrm{~kJ} /$ mol reported previously $/ 5 /$. Such a result would be consistent with that required to account for mechanical behavior data on $\mathrm{Nb}-\mathrm{O}-\mathrm{N}$ alloys and many other Group Vb ternary alloys which exhibit extrinsic solid solution softening $/ 16 /$. Fig. 2 illustrates such a result from the work of Ulitchny and Gibala $117 \%$. They have demonstrated that high purity $\mathrm{Nb}-\mathrm{O}$ and $\mathrm{Nb}-\mathrm{N}$ alloys deformed at low homologous temperatures exhibit typical solid solution hardening. However, the presence of $\mathrm{N}$ or $\mathrm{O}$ as a residual impurity or as a second solute intentionaliy added to the respective binary alloy results in solid solution softening, i.e. a yield stress less than that expected for any reasonable law of additivity of component yield stresses $/ 18 \%$. It should be noted from Fig. 2 that as little as 50 ppma of $\mathrm{N}$ in $\mathrm{Nb}-0$ causes solid solution softening. This is approximately the level of $\mathrm{N}$ estimated to be in Okamoto's material $19 \%$. It is reasonable that the same $0_{\mathrm{n}} \mathrm{N}$ solute clustering effects should be manifested in comparable internal friction and mechanical behavior experiments.

\section{ACKNOWLEDGEMENT}

This research was supported by the National Science Foundation, Grant No. DMR-8203078.

\section{REFERENCES}

/1/ Weller, M., Zhang, X., Li, G.Y., Kêe, T.S., and Dieh1, J., Acta Met. 29 (1981) 1047; ibid. 29 (1981) 1055.

12/ Powers, R.W., and Doyle M.J., J. Appl. Phys. 30 (1959) 514; ibid. Trans. Met. Soc. AIME 215 (1959) 655.

13/ Keefer, D. and Wert, C.A., Acta Met. 11 (1963) 489.

/4/ Gibala, R. and Wert, C.A,, Acta Met. 14 (1966) 1095; ibid. 14 (1966) 1105.

/5/ Gibala, R. and Wert, C.A., Trans. Met. Soc. AIME 236 (1966) 924.

16/ Ahmad, M.S. and Szkopiak, Z.C., J. Phys. Chem. Solids 31 (1970) 1799.

/7/ Tewari, S.N. and Cost, J.R., 5th Int. Conf. IFUAS (D. Lenz and $K$.

Lucke, eds.), p. 330. Springer, Berlin (1974).

18/ Okamoto, M.-A., Acta Met. 31 (1983) 1169.

19/ Cost, J.R., Acta Met. 32 (1984) 123.

/10/ Nowick, A.S. and Berry, B.S., IBM J. Res. Develop. 5 (1961) 297.

111/ Hoffman, R.A. and Wert, C.A., J. App1. Phys. 37 (1966) 237.

/12/ Miner, R.E., Gibbons, D.F. and Gibala, R., Acta Met. 18 (1970) 419.

113/ Perkins, R.A. and Padgett, Jr., R.A., Acta Met. 25 (1977) 1221.

114/ Tewari, S.N., Scripta Met. 8 (1974) 371.

/15/ Boratto, F.J.M., and Reed-Hi11, R.E., Scripta Met. 11 (1977) 709; ibid. 12 (1978) 313 .

/16/ Gibala, R. and Mitche11, T.E., Scripta Met. 7 (1973) 1143.

/17/ Ulitchny, M.G. and Gibala, R., J. Less-Common Metals 33 (1973) 105.

/18/ Browne, L.M. and Ham, R.K., Strengthening Methods in Crystals (A. Kelly and R.B. Nicholson, eds.), p. 12. Halsted/Wiley, New York (1971).

/19/ Ravi, K.V. and Gibala, R., Acta Met. 18 (1970) 623. 
Table 1

Investigations on Intexstitial Solute Anelasticity of BCC Metals

\section{A. Evidence for Solute Clustering}

Investigators

Powers and Doyle (1956-1959)

Keefer and Wert (1963)

Gibala and Wert (1966)

Ahmad and Szkopiak (1970)

Tewari and Cost (1974)

Okamoto (1983)

Cost (1984)

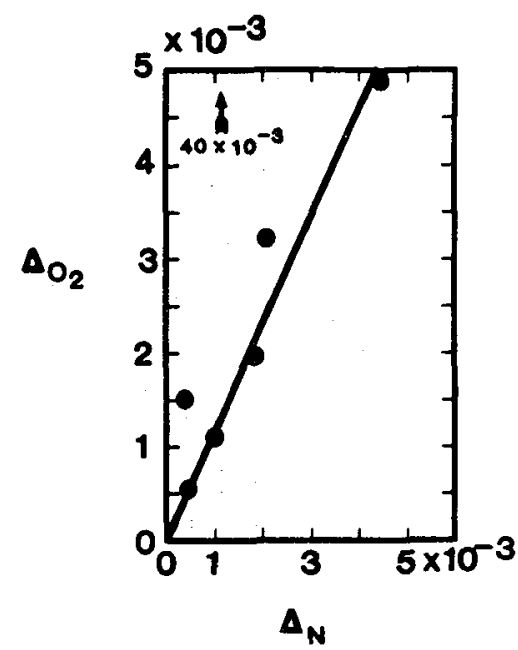

Fig. 1 - Relaxation strength of the oxygen pair relaxation in $\mathrm{Nb}-\mathrm{O}$ alloys observed by Gibala and Wert as a function of the residual nitrogen concentration.

2
3
4,5
6
7
8
9

B. Evidence for Lognorma1/Debye Behavior

Investigators

Reference

Hoffman and Wert (1966)

11

Miner, Gibbons and Gibala (1970) 12

Tewari (1974)

Perkins and Padgett (1977)

Boratto and Reed-Hil1 (1977-1978) 15

We1ler, Zhang, Li, Ke and Dieh1

(1981)

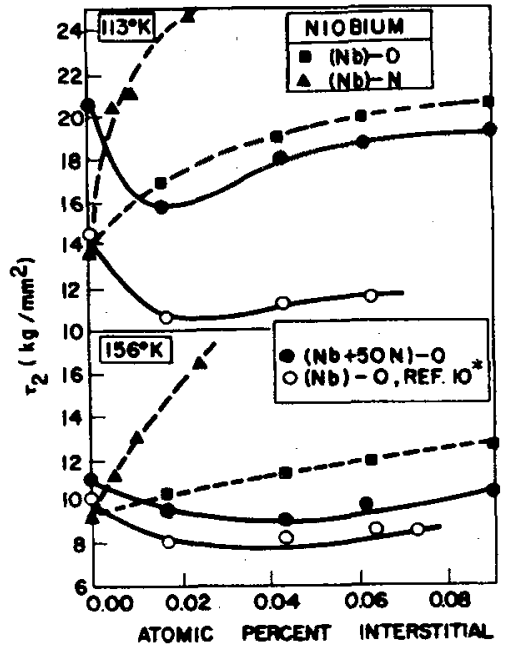

Fig. 2 - The effect of interstitial concentration on the flow stress of niobium single crystals with various background levels of interstitial solutes. (Ref. 10 refers to Ref. 19 in this paper.) 